Peer-Reviewed Article

OOJED

International Journal of Multidisciplinary

Perspectives in Higher Education

Volume 4, Issue 1 (2019), pp. 111-135

https://www.ojed.org/jimphe Print ISSN

2474-2546 Online ISSN 2474-2554)

\title{
Challenges Faced by International Students at Kwantlen Polytechnic University
}

\author{
Ashiq Ali Shah \\ Kwantlen Polytechnic University, Surrey, British Columbia, Canada \\ Email: ashiq.shah@kpu.ca \\ Alexander Lopes \\ Kwantlen Polytechnic University, Surrey, British Columbia, Canada \\ Email: alexander.lopes@email.kpu.ca \\ Linah Kareem \\ Kwantlen Polytechnic University, Surrey, British Columbia, Canada \\ Email: linahtk@gmail.com
}

\begin{abstract}
This study aimed to investigate the challenges international students face during their studies at Kwantlen polytechnic university. The research focused on the English language, study-related and financial issues, and adjustment to life in Canada. The participants were 25 females and 38 male students of 18- 35 years old from China, India and the Middle East. The materials included a challenges questionnaire, coping and religiosity scales, adjustment in Canada and religious involvement scales, and a demographic questionnaire. The data were collected at three campuses of KPU. The main challenges reported by the majority of international students were high tuition fees, high rents, part-time work, and missing the families. Most international students liked small class sizes, were satisfied with the education, felt comfortable communicating with professors, were welcomed by their peers and had adjusted to Canadian culture. In general, international students who used both emotion-avoidance and problem-focused coping strategies were better at facing challenges.
\end{abstract}

Keywords: Challenges, International students, three nationalities, Canadian University 


\section{Introduction}

The life of a student can often prove to be a challenging one. Being inundated with the stress of tuition, class responsibilities, maintaining a social life, and managing finances is a heavy burden on almost anyone. Now imagine this lifestyle in a land where very little is familiar. The language serves as a barrier, the culture is different than any that you are familiar with, the people are largely unknown to you, and your social support is an ocean away, a life typical of an international student (Russell, Rosenthal, \& Thomson, 2010). These difficulties are compounded because, despite the general perception that North American culture is based around diversity, there exists a mindset that Eurocentric culture is superior to others. Hence, those who come to be a part of North America may feel pressure to conform to the homogeneous cultural climate (Hsieh, 2007). A narrative study conducted with a Chinese woman studying in America asks a question of what it is to be invisible. She responds that to be invisible does not mean that something does not exist. Instead, it is the social structures that force people to be invisible and voiceless (Hsieh, 2007). For her being different implied that she could not be a part of the group leading her to internalize a negative self-perception as a marginalized person (Hsieh, 2007).

Unlike its other Western counterparts like the UK, U.S., Europe, and Australia, Canada was not the first choice for international students a couple of decades ago. The rapidly changing geopolitical world circumstances have necessitated a shift toward the internationalization of education at the Canadian universities. Some research indicates that international student program are driven by financial benefits for universities. The income from international students in the United Kingdom, for example, makes up for almost a third of all the earnings of universities and colleges (Brown \& Jones, 2013). However, a more valuable benefit is found in a diversity of culture and mind that international student programs provide.

While the U.S. has experienced a decline in international students, primarily due to Trump's administration's anti-immigration and racist policies, the number of international students at Canadian universities has increased exponentially. A big majority of these students come from the new emerging economies in South and South-East and Middle East regions. The latest enrolment data show that international student enrolment at Canadian universities has risen by 11 percent in the year 2016 (Universities Canada, November 15, 2017). Almost all provinces across the country saw a rise in international student enrolment; however, British Columbia was ahead of all other provinces with a 15.6 percent increase. Kwantlen Polytechnic University has seen a $174 \%$ increase in the number of international students, especially from India in the Fall semester 2017.

As international students come from diverse regions of the world, they also bring their cultural traditions and academic mindset to the host 
culture. The differences in the culture and the traditions of the international students and the social and academic environment of the educational institutions in Canada create a heterogeneous mixture of idiocentric and allocentric values (Triandis, Leung, Villareal \&Clack, 1985) of individualist and collectivist cultures. This presents a challenge for the academic staff how to bridge the expectations of international students and academic standards of the institution. This point highlights the importance of research being conducted for the benefit of these students. Some research studies show that while there is a large volume of international students in Canada, they face cultural and linguistic barriers (Arthur \& Flynn, 2011; Ge, Brown \& Durst, 2019), difficulties in connecting to host communities and perceived employer discrimination (Scott, Safdar, Desai Trilokekar \& El Masri, 2015; Ge et al., 2019). A study by Brown and Jones (2013) on incidences of racism against international students found that out of a group of 153 international students, a staggering 49 had experienced some form of racist assaults, which were both verbal and physical in nature. The authors suggest that universities should focus on how international students adjust to life on the campus rather than on financial gains (Brown \& Jones, 2013).

For international students, it may feel hard to bridge cultural differences at the beginning (Baklashova \& Kazakov, 2016), and the language may be a daunting barrier to get to know people in a new environment and the local students (Jenkins \& Galloway, 2009). In addition to linguistic and cultural barriers, another big challenge for international students is to build social relationships with domestic students (Elturki, Liu, Hjeltness \& Hellmann, 2019). Other more difficult challenges may include having to supplement or pay the entirety of their tuition by finding work in a place and a job that is completely unfamiliar.

In addition to language and social barriers faced by international students, the study by Russell et al. (2010) on how international students adapt to their unfamiliar surroundings found three patterns of responses. These patterns included positive and connected, unconnected and stressed, and distressed and risk-taking. The majority of students (nearly 60\%) reported a style of adaptation that was a positive one - implying that they were adjusting well to their new environment. However, the remaining students reported their general affect and attitude towards their situation as stressful (Russell et al., 2010). As previously mentioned, research suggests that more than the everyday challenges of being a student or feelings of homesickness, it is feeling cut off from social support that results in a negative outlook for international students (Hsieh, 2007).

Furthermore, there might be certain unique challenges faced by international students studying at universities in different provinces of Canada. For example, the students studying at the universities at Eastern Canadian universities have to acclimatize to extreme weather conditions but may encounter more friendly and welcoming folk, whereas students studying 
at the universities in Quebec may experience prejudice and discrimination in addition to harsh weather conditions. The situation at the universities in Western Canadian provinces might provide opportunities to international students in a somewhat different context.

The aim of this study was to investigate what challenges international students face as well as the way in which they respond to those challenges during their studies at Kwantlen Polytechnic University (KPU), one of the leading universities in Western Canada. Specifically, we focused on English language challenges, study-related issues, financial challenges, and challenges related to adjusting to life in British Columbia. The hypotheses of our study pertaining to these challenges included:

(1) Students from China will report more language-related challenges than students from South Asia and the Middle East.

(2) Students from Middle Eastern countries will report more studyrelated challenges than South Asian or Chinese students.

(3) Students of South Asian origin will report more financial challenges than then Middle Eastern or Chinese students.

(4) Female international students will report more adjustment issues than their male counterparts.

We examined the coping methods international students might employ when facing challenges. For our purpose, we looked at the problem focused and emotion-focused coping. We formulated the following hypotheses.

(5) Chinese students will report using problem-focused coping more than Middle Eastern and South Asian students, and; Middle Eastern students will report using emotion-focused coping more than Chinese and South Asian students.

We further examined religiosity to see differences in the religiosity of international students belonging to different nationalities. We wanted to know whether religious beliefs and practices of international students would be helpful in dealing with the challenges. Our hypotheses included:

(6) Middle Eastern students will score higher on religiosity than Chinese and South Asian students, and religious practices will be helpful for international students to deal with the challenges.

In addition, we were interested to see relationships between religiosity and two types of coping strategies. We expected that international students who are religious would use more emotion-avoidance coping rather than problem-focused coping. We hypothesized that:

(7) Students who score high on religiosity will report using more emotion-avoidance coping, but less problem-focused coping. 


\section{Method}

\section{Participants}

The participants were 25 female and 38 male international students in the age range of 18- 35 years who were enrolled in an undergraduate program at KPU. The participants included 22 Chinese, 26 Indians, and 15 Middle Eastern nationals. Their study year and the duration of stay in Canada ranged from 1-7 years. The participants had diverse religious backgrounds including 18 Muslims, 20 Sikhs, 4 Hindus, 4 Buddhists and 17 with no religious affiliation.

\section{Materials/scales}

The materials used included three scales; a challenges questionnaire, a coping scale, and a religiosity scale. Besides, one item adjustment in Canada and religious involvement rating scales and a demographic questionnaire were also used.

\section{Challenges scale}

A group of four senior undergraduate students attending an upperlevel course on 'cultural psychology' formulated statements on challenges faced by the students, especially considering the unique situation of international students at Canadian universities and in everyday life situations. The statements covered different areas pertaining to the life of an international student including English language, study-related issues such as coping with the stress of school work, interaction with the local classmates and communication with the professors, adjustment to the university environment, financial challenges, accommodation and transportation challenges, daily recurring situations (e.g., contact and interaction in the community), finding part-time work, social support, local climate, experiences of discrimination and adjusting to life in British Columbia. The statements were scrutinized for the appropriateness of the content, language and intelligibility by the principal investigator and two research assistants. A hundred percent agreement was used for the selection of the statements. Finally, a total of 30 statements were selected called 'Challenges scale.'

There were 20 positive statements like, "I find it easy to maintain my expected grade" and ten negative ones such as, "I am overwhelmed by my school work." Each statement had a five-point Likert type scale with the evaluative categories of 'strongly agree,' 'agree,' 'neither agree nor disagree,' 'disagree,' and 'strongly disagree.' The minimum score on the scale was 30 , and the maximum was 150 . The higher the score the greater the challenges encountered by the participants. 


\section{Coping scale}

The Brief COPE (Carver, 1997), which is a short version of the COPE, was adapted and used to measure coping strategies used by international students. The original Brief COPE includes 28 items with 14 subscales containing two items each; however, the factor analysis of Brief COPE showed four distinct factors. The items of the scale are scored on a four-point Likert type scale. We selected 19 items suitable for our study which included 11 items of problem-focused coping and eight items of emotion/avoidance coping. The items of the scale had a five-point Likert type scale. The minimum score on the scale was 19 and a maximum of 95. Carver (1997) has recommended that researchers use scale flexibly as it suits their research design. An example of problem-focused coping is, "I try to come up with a strategy about what to do," and that of emotional/avoidance coping is, "I seek emotional support from others." The internal consistency reliability of the coping scale was .613.

\section{Religiosity scale}

The religiosity scale consisted of nine items, which were scored on a five-point Likert type rating scale. Four items were adapted from Ashdown, Homa, and Brown's (2014) religious identity scale, which measured interdependence and attachment to the religious group, content and meaning of being religious, and self-categorization as being religious. Five other items were added of which four pertained to satisfaction with one's life and one item to allow for religious non-affiliation. The religious non-affiliation item was reverse coded. An example of a religiosity item is, "My religion is an important part of my identity." An item measuring one's satisfaction with life is "I live my life according to my ideal," and the item on religious nonaffiliation is, "I do not belong to any religious faith." The internal consistency reliability analysis of the religiosity scale showed an alpha of .655.

\section{Demographic questionnaire}

A demographic questionnaire was designed to collect information on international student's age, gender, a program of study, religious background, type of financial support, year of study, and the duration of stay in Canada. A five-point Likert type rating scale, ranging from "not at all" to "always," was included on the demographic questionnaire to measure the religious involvement of internationals. The demographic questionnaire also included another five-point Likert type rating scale on which the participants were asked to rate how well they were adjusted in Canadian society. It ranged from 'very poor' to "very well adjusted." The type of financial support included three options, namely, 'scholarship,' family support,' and 'self.' The participants had the choice to select one or more than one option. 


\section{Procedure}

The participants for this study were recruited at the Kwantlen Polytechnic University Surrey, Richmond, and Langley campuses. International students were contacted in-person by the research assistants around students' meeting areas, e.g., libraries, international office, cafeteria, through friend's circles at the three campuses. In addition, university professors were requested to allow recruiting international students from their classes. Online recruitment was another avenue for recruiting. Posters and advertisements were placed on KPU's International Students Page and the notice boards of the university campuses. International students taking psychology courses were able to sign up through the SONA system of psychology lab. The purpose of the study was explained to the participants and then a consent form was handed out to them which informed them on the confidentiality of their data, that there was no harm to them regarding their participation and that they could withdraw from the study at any time if they so desired. After signing the consent form, participants were given the research questionnaire and were told to indicate their level of agreement with each statement by selecting a number on the five-point rating scale. They were also asked to complete demographic information towards the end of the survey. Participants were told to complete all the sections of the questionnaire and were assured that their responses will remain anonymous and will be used only for research purposes. International students taking psychology courses were entitled to a bonus credit towards their eligible courses. In the end, they were handed out a debriefing form that explained the actual purpose of the study and had the contact information of the principal investigator to be contacted for any future inquiries and on the outcome of the study. This study was approved by the 'Research and Ethics Board' (REB) of KPU.

\section{Results}

The data were analyzed with descriptive statistics to obtain information on the demographic information and the most important challenges encountered by international students at Kwantlen Polytechnic University. The data were also analyzed with one factor between-subject analysis of variance on the total challenges scores of three groups of international students for differences in challenges faced by them. One factor between subject analyses of variances were also computed on the scores of three groups of international students for differences on each item of the challenges scale. To find out differences in religiosity and religious involvement of three groups of international students and whether they differ in their use of problem-focused and emotion-avoidance coping strategies, one factor between subject analyses of variances were performed. A multiple regression analysis was computed employing challenges score as the criterion and problem-focused, emotion-avoidance copings, religiosity, and religious involvement as the predictor variables to find out what predictors are 
employed by the international students to deal with the challenges faced by them.

The data were analyzed to compute the mean and standard deviations on the scores of international students on individual items of the challenges scale. A mean of more than 3.5 was used as a cutoff score to determine a significant challenge faced by international students.

The results showed the highest mean score, Mean $=4.47$, S.D. $=0.89$ on item 22 (I think it is unfair that international students pay a higher rate for education). The second highest mean, Mean $=4.33$, S.D. $=0.86$ was observed on item 30 (I receive support from my family back home) and the third highest mean score, Mean $=4.31$, S.D. $=0.73$ was on item 6 (I like the small class sizes at Kwantlen). The fourth highest mean, Mean $=4.25$, S.D. $=1.03$, was on item 29 (I miss my family). Other challenges faced by international students in the order of the highest mean scores were, item 1 , Mean $=4.06$, $S . D .=0.83$ (I have a good understanding of English language), item 2, Mean $=4.03, S . D .=0.77$ (I am welcome by my peers), item 19, Mean $=3.98$, S.D. $=0.90$ (I am happy with the education received in Canada), item 28, Mean $=$ 3.92, S.D. $=1.16$ (I miss my country), item 4, Mean $=3.90$, S.D. $=0.89$ (It's difficult to find affordable rent), item 21, Mean $=3.85$, S.D. $=1.02$ (I would enjoy the experience of part-time work), item 9, Mean $=3.79$, S.D. $=0.95$ (I feel comfortable to communicate with my professor in the class), item 23, Mean $=3.73$, S.D. $=1.18$ (Given the opportunity I would like to live on campus), item 20, Mean $=3.71$, S.D. $=0.85$ (I need to financially supplement my education), and item 26, Mean $=3.61$, S.D. $=0.95$ (I have adjusted to the culture of Canada).

The results of one factor between subject analysis of variance on the total challenges scores of three groups of international students in Table 1 shows a significant difference for three groups of students, $F(2,60)=6.292$; $p<.003$. The effect size, $\eta^{2}$ was 0.17 . This means $17 \%$ of the total variance was explained by the variation in the independent variable. The mean challenges score of Indian students was highest 109.46, followed by the students from Middle East 106.27 and Chinese students 103.0. This shows that Indian faced the greatest challenges among the three groups of international students. The posthoc comparison using Tukey HSD indicated an only significant difference between Indian and Chinese students, mean difference $=-6.46$; standard error $=1.8, p<.002$. 
Table 1: One-way, Between-Subject ANOVA on the challenges scores of international students from China, India, and the Middle East studying at Kwantlen Polytechnic University (KPU), Surrey, BC.

\begin{tabular}{|l|l|l|l|l|l|}
\hline $\begin{array}{l}\text { Source of } \\
\text { variance }\end{array}$ & $\begin{array}{l}\text { Sum of } \\
\text { Squares }\end{array}$ & df & Mean Square & F & Sig. \\
\hline $\begin{array}{l}\text { Between } \\
\text { Groups } \\
\text { Within Groups }\end{array}$ & 498.161 & 2 & 249.080 & 6.292 & .003 \\
Total & 2375.395 & 60 & 39.590 & & \\
\hline
\end{tabular}

One factor between subject analyses of variances were performed on the scores of three groups of international students for all 30 items of challenges scale. The result showed significant outcomes for items $1,5,6,8$, $9,17,22$ and 27. The findings on other items of the scale were not significant. The results on "good understanding of English language" (item 1) indicated a significant difference for the three groups, $F(2,60)=4.9, p<.01, \eta^{2}=0.14$. The mean score of Indians was highest $(M=4.31, S . D .=.88)$ followed by the Middle Eastern $(M=4.26, S . D .=.59)$ and the Chinese $(M=3.6, S . D .=$ .78). This means that Indians had a better knowledge of English language compared to Middle Eastern and Chinese students.

The "preference to live alone" (item 5) showed a significant difference between the three groups of international students, $F(2,60)=3.67$, $p<.03, \eta^{2}=0.11$. The Indians had the highest preference to live alone $(M=$ 3.38, S.D. $=1.4)$ followed by Middle Eastern $(M=2.87, S . D .=1.1)$ and the Chinese $(M=2.45$, S.D. $=.96)$.

The international students also differed on "liking for the small class size" (item 6), $F(2,60)=3.46, p<.03, \eta^{2}=0.10$. Indian students liked the small classes most $(M=4.5, S . D .=.76)$ followed by the Chinese $(M=4.3$, S.D. $=.56)$ and the Middle Eastern students $(M=3.9$, S.D. $=.79)$.

For some international students "classes were stress free" (item 8) compared to others, $F(2,60)=12.33, p<.0001, \eta^{2}=0.29$. Indian students feelings of classes as stress free was highest $(M=4.15$, S.D. $=1.0)$, whereas Chinese students scored least $(M=2.81, S . D .=1.0)$ and Middle Eastern students had almost the same score as the Chinese $(M=2.86$, S.D. $=1.0)$. 
There were also differences among international students regarding how "comfortable they felt communicating with their professors" (item 9), $F$ $(2,60)=4.14, p<.02, \eta^{2}=0.12$. The results showed that Indian students felt most comfortable to communicate with their professors $(M=4.1, S . D .=.86)$, followed by Middle Eastern $(M=3.87, S . D .=.91)$ and the Chinese students $(M=3.3$, S.D. $=.95)$.

An interesting finding was observed regarding the difference among international students on the "extent of pressure they felt to succeed" (item $17), F(2,60)=4.42, p<.01, \eta^{2}=0.13$. The Chinese students had the highest mean on feeling pressure to succeed $(M=3.86, S . D .=.63)$, followed by Middle Eastern students $(M=3.66$, S.D. $=1.17)$, whereas Indian students felt the least pressure to succeed $(M=3.00, S . D .=1.23)$.

Differences were also found on item 22 regarding "higher tuition fees for international students which they thought was unfair", $\mathrm{F}(2,60)=4.3, p<$ $.01, \eta^{2}=0.13$. Indian students had the highest score on the unfairness of higher tuition fees for international students $(M=4.8, S . D .=.46)$ followed by Chinese $(M=4.2$, S.D. $=.93)$ and the Middle Eastern students $(M=4.1, S . D$. $=1.18)$. International students also differed on their liking of Vancouver weather, $F(2,60)=6.86, p<.002, \eta^{2}=0.19$. International students from Middle East liked Vancouver weather most $(M=3.8, S . D .=.99)$ followed by Indian $(M=3.69, S . D .=1.12)$ and by the Chinese students $(M=2.68$, $S . D .=1.04)$ respectively.

One factor between subject analysis of variance on the problemfocused and emotion-avoidance coping scores of three groups of international students were not significant. However, one factor between subject analysis of variance on the religiosity scores of three groups of international students indicated a highly significant difference, $F(2,60)=21.15, p<.0001, \eta^{2}=$ 0.41 . The Middle Eastern students were most religious $(M=36.40, S . D .=$ $2.35)$ followed by the religiosity scores of Indians $(M=31.11$, S.D. $=4.47)$ and the Chinese $(M=26.13, S . D .=6.04)$.

One factor between subject analysis of variance was also performed on the religious involvement scores of three groups of international students, which also showed a highly significant difference regarding religious practices of international students, $F(2,60)=27.73, p<.0001, \eta^{2}=0.48$. The Middle Eastern students were found to be most religiously involved $(M=$ 4.53, S.D. $=.63)$ followed by the religious involvement of Indians $(M=3.03$, $S . D .=.99)$, whereas the Chinese students were least religiously involved $(M$ $=1.90$, S.D. $=1.30$ ).

A t-test for independent samples was conducted to find out gender differences in the challenges faced by female and male international students. The outcome of the analysis was not significant indicating that female and male students did not differ on encountering challenges during their education at KPU, $\mathrm{t}_{05}(61)=-.079$, n.s. This outcome is contrary to our hypothesis that 
female international students will face more challenges compared to their male counterparts.

We also performed a multiple regression analysis using the challenges scores as the criterion and problem-focused coping, emotion avoidance coping, and religiosity as a predictor to determine what variables would be useful predictors of challenges encountered by international students. The outcome of regression as depicted in Table 2 was significant, $F$ $(4,58)=5.12, p<.001$. Table 3 shows the multiple correlation of $R=.511$, $R^{2}=.261$ and adjusted $R^{2}=.210$. (standard error of estimate $=6.0 ;$ DurbinWatson statistics $=1.9$ ). Table 4 indicates that the only significant predictor of challenges faced by international students found was problem-focused coping with a significant beta value, $\beta=.374, t=2.915, p<.005$. This means that problem-focused coping was an effective way for international students to face the challenges.

Table 2. Multiple Regression analysis, $F$ value, Degrees of freedom, and Significance

of $F$ for the predictors of challenges faced by international students at KPU.

\begin{tabular}{|ll|l|l|l|l|l|}
\hline \multicolumn{2}{|c|}{ Model } & $\begin{array}{l}\text { Sum of } \\
\text { Squares }\end{array}$ & $\mathrm{df}$ & $\begin{array}{l}\text { Mean } \\
\text { Square }\end{array}$ & $\mathrm{F}$ & Sig. \\
\hline 1 & Regression & 749.929 & 4 & 187.482 & 5.120 & $.001^{\mathrm{a}}$ \\
& Residual & 2123.626 & 58 & 36.614 & & \\
\multicolumn{2}{|c|}{ Total } & 2873.556 & 62 & & & \\
\hline
\end{tabular}

a. Predictors: (Constant), Religious involvement, Religiosity, Emotionavoidance coping (EA), and Problem-focused coping (PF).

Dependent Variable: Challenges scale

Table 3: Multiple correlation coefficients, standard error, and DurbinWatson

Statistics for predictors of challenges faced by international students at KPU.

\begin{tabular}{|l|l|l|l|l|l|}
\hline Model & $R$ & R Square & $\begin{array}{l}\text { Adjusted R } \\
\text { Square }\end{array}$ & $\begin{array}{l}\text { Std. Error of } \\
\text { the Estimate }\end{array}$ & $\begin{array}{l}\text { Durbin- } \\
\text { Watson }\end{array}$ \\
\hline 1 & $.511^{\mathrm{a}}$ & .261 & .210 & 6.05097 & 1.986 \\
\hline
\end{tabular}

a. Predictors: (Constant), Religious involvement, Religiosity, Emotionavoidance coping (EA), and Problem-focused coping (PF). sendent Variable: Challenges scale 
Table 4. Unstandardized and Standardized Coefficients, and $t$ Values for Multiple-Regression Analysis of predictors of challenges faced by international students at KPU.

\begin{tabular}{|c|c|c|c|c|c|c|c|}
\hline \multirow[b]{2}{*}{ Model } & \multicolumn{2}{|c|}{$\begin{array}{l}\text { Unstandardiz } \\
\text { ed } \\
\text { Coefficients }\end{array}$} & \multirow{2}{*}{$\begin{array}{l}\text { Standardi } \\
\text { zed } \\
\text { Coefficie } \\
\text { nts }\end{array}$} & \multirow[b]{2}{*}{$\mathrm{t}$} & \multirow[b]{2}{*}{ Sig. } & \multicolumn{2}{|c|}{$\begin{array}{l}95.0 \% \text { Confidence } \\
\text { Interval for B }\end{array}$} \\
\hline & B & \begin{tabular}{|l} 
Std. \\
Error
\end{tabular} & & & & $\begin{array}{l}\text { Lower } \\
\text { Bound }\end{array}$ & $\begin{array}{l}\text { Upper } \\
\text { Bound }\end{array}$ \\
\hline $1 \quad$ (Constant) & $\begin{array}{l}69.60 \\
9\end{array}$ & 8.357 & & $\begin{array}{l}8.3 \\
29\end{array}$ & .000 & 52.880 & 86.337 \\
\hline $\mathrm{RI}^{\mathrm{a}}$ & -.427 & .818 & -.090 & $\begin{array}{l}- \\
.52 \\
2\end{array}$ & .604 & -2.064 & 1.210 \\
\hline Religiosity $^{\mathrm{a}}$ & .265 & .199 & .237 & $\begin{array}{l}1.3 \\
34\end{array}$ & .187 & -.133 & .663 \\
\hline $\mathrm{EA}^{\mathrm{a}}$ & .188 & .244 & .098 & $\begin{array}{l}.76 \\
9\end{array}$ & .445 & -.301 & .676 \\
\hline $\mathrm{PF}^{\mathrm{a}}$ & .610 & 209 & .374 & $\begin{array}{l}2.9 \\
15\end{array}$ & .005 & .191 & 1.029 \\
\hline
\end{tabular}

b. Predictors: (Constant), Religious involvement (RI), Religiosity,

Emotion-avoidance coping (EA), and Problem-focused coping (PF). sendent Variable: Challenges scale

Correlation coefficients were also computed to see the relationship between religiosity and problem-focused, emotion-avoidance strategies and the challenges faced by the international; and also between involvement in religious practices and problem-focused versus emotion-avoidance coping by the participants. The results showed a significant correlation between religiosity and the use of emotion-avoidance type of coping, $r=.293, n=63$, $p<.01$. This is consistent with our hypothesis that religiosity of international students will be related to their emotion-avoidance coping approach. There was also a significant correlation between religiosity and problem-focused coping, $r=.304, n=63, p<.008$. This outcome is unexpected as we assumed that religiously involved internationals would score low on problem-focused coping. The correlations computed were all one-tailed.

\section{Discussion}

The findings of this study revealed that international students studying at Kwantlen Polytechnic University encountered a number of challenges while being in Canada. The responses of international students indicated that their main concern was the high tuition fees compared to local students, which they found unjust. Moving to a new country is itself costly 
and charging high tuition from international students may overburden them financially. Research studies on international students elsewhere also found that the cost of tuition was ranked highest amongst other problems cited by international students (Robertson, Line, Jones, \& Thomas, 2010). This shows that irrespective of the country of stay, the international students feel overburdened by the high education cost. The financial woes may be felt more by the students coming from underdeveloped or developing countries or by those not sponsored by their governments.

The next important issue indicated by international students was the support they receive from their families back home. Family support plays a huge role in the lives of international students, especially at the beginning of their studies in a new country. After leaving their countries and without much social support in a new country, a considerable majority of international students report feeling isolated and lonely, especially in the early months of their arrival (Sawir, Marginson, Deymert, Nyland, \& Ramia, 2008). The majority of international students also indicated that they missed their families and country. The sheer distance of North America from the countries of their origin may be a psychological factor in the perception of international students that they are far away from their families and home country. Our view is consistent with the findings of Mooney, Sherman and Presto (1991), which found the perception of the distance from home as one of the four contributing factors in the adjustment of female college freshmen. The feelings of loneliness represent international students' deep attachment to the values, the culture, and social relationships which they left behind may be a formidable challenge for them to connect with the people in the new environment (Elturki et al., 2019). Strong feelings of missing one's family and the country may have a negative emotional impact on the wellbeing of international students adding to their hardship compared with domestic.

Of positive note is that participants in our study mentioned that they were welcomed by their peers, which means that they did not encounter social barriers while connecting with their classmates, whether they are local or international. Connecting with other students would be beneficial for international students in many ways. This can help internationals to develop a sense of belongingness, reducing their feelings of isolation and increasing their engagement in the broader social context (Sherry, Thomas \& Chui, 2010).

International students also showed their liking for small classes at KPU. The maximum number of students in a class at KPU is 35 . The positive feelings of students toward the educational setup of an institution can have a positive impact on the learning of the students. The small class sizes promote a more interactive teaching-learning atmosphere and support students' participation in in-class activities. International students who are new to the educational system in Canada may find it difficult to learn in big lecture halls with minimum chances of contact with the professors and their classmates. 
Small classes at KPU also foster group work and interactions among students and professors which may help students to achieve their educational goals. Empirical findings are supportive of our idea, which found that students who were in small group learning achieved higher grades on the final exams when compared to students who learned individually (Guadet, Ramer, Nakonechny, Cragg, \& Ramer, 2010).

A positive experience of participants in our study was their satisfaction with education as the majority of them reported that they were satisfied with the education they are getting in Canada. A diverse postsecondary education in Canada that involves not only lecture-style teaching but also includes group work, class activities, project work, experiential learning, and community-based programs may be novel and enriching experiences for the international students. As the Canadian educational system encourages the active involvement of students in learning, this may give the internationals to explore and utilize their potential, leading to their satisfaction. The international students' liking for the small class sizes at Kwantlen may be another reason for their liking of education in Canada.

As against our expectations, international students reported having a good understanding of the English language. This may be because of the fact that people all over the world have considerable exposure to the English language through the mass media, internet and the entertainment industry. In addition, technological advancements and high tech challenges make the use of the English language indispensable. The educational systems around the world are incorporating learning of the English language as part of their education. English language courses during the orientation period at KPU might have been helpful in acquiring English language competency by international students. Another reason for this outcome may be a greater number of international students from India who come with a background of English medium instructions. The high scores of Indian students might have masked the responses of other international students, for example, from China who faces problems with the English language (Ge et al., 2019). There might also be differences in the competency between spoken and written language as a study by Sherry, Thomas and Chui (2010) shows that students in their study emphasize spoken language barriers far more than written language problems.

Participants in our study, however, faced the challenge of living off campus and they expressed the desire to live on campus (KPU does not have hostel facilities). Living on-campus is more affordable as off-campus housing is more expensive. By living on-campus international students can avoid paying high rental and save some money for tuition and other daily expenses (Calder, Ritcher, Mao, Burns, Mogale \& Danko, 2016). Campus living also offers a unique living and learning atmosphere that promotes academic achievement, enriches a student's academic experience and promotes one's intellectual and self-development (Mohd Najib, Yousaf \& Tabassi, 2015). 
Living on campus means easy access to the commons, computer labs, athletic facilities, and sporting, social, and cultural events.

The majority of the participants in our study struggled to find affordable housing in local communities, a huge problem for internationals at KPU. After opening its doors to international students and lacking on-campus residences, it has inadvertently put international students in a precarious situation. Although the international student office of KPU assists internationals in finding reasonable rent, rental accommodation in the surrounding areas of KPU campuses is expensive. Expensive off-campus living may drain the limited financial resources of international students, which may adversely affect the overall quality of their lives. The expensive off-campus rental housing seems to be a problem for the international students in Western Canadian cities as some studies show that international students end up spending more than $30 \%$ on their income on off-campus rent (Calder et al., 2016).

Many participants in our study expressed the desire to work part-time to supplement their education. Finding part-time work may pose a considerable challenge for the internationals in an unfamiliar social environment. Part-time work may help international students to pay school tuition and rent, and meet their daily needs (Calder et al., 2016). Through parttime work, international students can also gain Canadian work experience during their studies that may increase their chance of finding a job later. However, the temptation to work lures some internationals toward a pitfall they may not be able to anticipate. In many cases, they become the victim of exploitative local small businesses that entice vulnerable students in need of money to illegal work. These students are paid just a fraction of the minimum wage under the table for long work hours. These students mostly stay away from their classes and end up failing their courses.

International students also reported that they have adjusted to the Canadian culture. This is a good sign of their ability to settle down in a new environment. A good understanding of the English language, to be welcomed by their peers, their ability to communicate with their professors, their satisfaction with the education they are receiving, and their feelings of being supported by their families might be important factors in their adjustment in the Canadian culture. Still, the negative impact of financial hardship in the form of high tuition fees, rental costs and other personal challenges cannot be ignored.

\section{In-depth comparisons among nationalities}

The differences in the responses of three groups of international students on the challenges scale and on the individual items of the scale show some important contrasts regarding the challenges faced by them. Among the three groups of international students, Indians faced the most challenges compared to the Middle Eastern and Chinese students. The specific socio- 
cultural background of three groups might be one of the reasons for these differences. The differences among Indians, Middle Eastern and Chinese on the individual items of challenges scale indicated that Indians had a better knowledge of the English language, preferred to live alone, like small classes at Kwantlen, found the classes as stress-free and felt comfortable communicating with the professors.

On the other hand, Chinese students had weak knowledge of the English language, found classes as stressful, had difficulty communicating with their professors and experienced discrimination compared to the other two nationalities. The significant challenge the Chinese students faced was the pressure to succeed. Taken together, feeling intense pressure to succeed while finding the classes less stress-free by the Chinese students can be understood in the backdrop of Chinese cultural traditions (Lin \& Qinghai, 1995). In the Chinese cultural tradition of filial piety, parents have high expectations from their elder children, especially the male children who are regarded as the successor of their father and are expected to take care of their parents and younger siblings (Matsumoto \& Juang, 2017). The Chinese students take their studies seriously and work hard to succeed (Neuby, 2012). The Chinese students are also supported by their parents, many of whom downgrade their way of living in order to offer their kids a shot at education to obtain the "Chinese Dream", which is the ideal lifestyle valued by the Chinese population. This is an understandable reason for the high expectations of parents toward their children. This results in students working astonishingly hard to study and to overwork to an unhealthy level. However, unfortunately, for some students, the pressure and stress associated with school is just too much to handle and pushes them to commit suicide or to simply quit school (Lin \& Qinghai, 1995).

The highest scores of Middle Eastern students on 'overwhelmed by schoolwork', 'exhausted at the end of the school day,' 'and 'school work makes me anxious,' and their lowest scores on 'liking for small classes,' and 'it is easy to maintain my expected grades' supports our hypothesis that Middle Eastern students will face more study-related challenges. Also, their lowest scores on 'high tuition fee,' 'affordable rent,' financially supplementing one's education,' 'part-time work' indicates their lack of financial concerns as they are sponsored by their government, which pays for their tuition, rent and the cost of living.

\section{Internationals coping strategies}

Our hypotheses regarding the difference between different national groups of international students on the use of problem-focused and emotionavoidance coping strategies were not confirmed. We assume that the three groups of internationals might have employed both types of coping strategies to face challenges. Some supporting evidence comes from a study by Wang (2009), indicating that one of the reasons for the resilience of international 
students was their use of a broad range of strategies to cope with their difficulties. Similarly, a study by Khawaja and Stallman (2011) found that international students use their personal experiences and strategies to cope with the challenges they face. Another study found that although international students faced adjustment and academic problems, faculty and staff overstated those (Jenkins \& Galloway, 2009).

\section{Nationalities and religiosity}

Our hypotheses pertaining to the differences in the religiosity of three groups of students were supported. The internationals from the Middle East were more religious and also more involved in religious practices than the Indians and the Chinese. The majority of Middle Eastern students come from Muslim majority countries where the majority of the population practices religious rituals on a daily bases (Nassar-McMillan \& Hakim-Larson, 2011). Religiously involved individuals were found to show resilience in the face of risk factors (Werner \& Smith, 1989) and were better at coping with the difficult life circumstances (Donelson, 1999). A study by Zullig, Ward and Home (2006) indicated that students who described themselves as spiritual or religious consistently reported greater self-perceived health. Religious individuals have healthy lifestyles and they are better able to overcome everyday life stresses (Benjamins, Ellison \& Rogers, 2010; Koenig King, \& Carson, 2011; McCullough \& Willoughby, 2009; Park, 2007). Religiosity may also act as a buffer against a number of physical and psychological problems, such as physical health (Rippentrop, Altmaier, Chen, Found and Keffala, 2005), anxiety (Koenig, 2009, 2012) and depression (Koenig, 2009; Shah, 2017; Siddiqui \& Shah, 1997).

\section{Gender and challenges}

Contrary to our expectation, we found no difference between female and male international students on the challenges faced by them. We assume that irrespective of the gender, the international students who come to Canada for postsecondary have the desire to learn and achieve their goals. They try hard to adjust to the cultural environment of Canada and to excel in their studies. Our view is in accordance with the finding by Baklashova and Kazakov (2016), which indicated that after facing a series of transitional difficulties at the beginning of their studies, these problems motivated international students to develop strategies to meet these challenges.

\section{Coping strategies and challenges}

The multiple regression analysis using challenges scores as criterion and emotion-avoidance and problem-focused coping, the religiosity of the participants, and their religious involvement as predictors found problemfocused coping as the only predictor of challenges. This means that problemfocused students face issues head-on and try their best to overcome them 
(Khawaja and Stallman, 2011; Wang, 2009). Research shows that while facing challenges to adapt to the new culture, coping strategies and the ability to deal with stress was very helpful for international students (Deardorff, 2006; Gebhard, 2012). It was also found that international students' use of coping or stress-resistance resources were related to their satisfaction with personal and university life (Mak, Bodycott, Ramburuth, 2015). This suggests that the best option for international students without the family and the familiar social support system is to use their efforts and potential to face challenges.

The correlational findings indicated that religiously students oriented reported using emotion-avoidance coping while facing challenges. This finding is in line with previous research that also found a positive correlation between religiosity and avoidance coping (Krok, 2016). We assume that religious individuals seek comfort in turning to prayer in the face of adversity rather than making the adversity their primary focus. Contrary to our hypothesis, students who were religious also used problem-focused coping. Our results do not explain why religiously involved internationals have used both types of copings. However, consistent with our findings, a study by Alsahafi and Shin (2017) demonstrates Saudi students' active use of various coping strategies to improve their language competencies, time management, and mixing with other students.

Other research studies on the link between religiosity and coping styles have differentiated between different problem-solving styles which show diverse role religion plays in problem-solving process (Pargament, Kennell, Hathaway, Grevengoed, Newman, \& Jones, 1988); a problemsolving style which involves active personal exchange with God (collaborative); a style in which the individual waits for solutions from God (deferring); and a style in which people believe that they have the choice to direct their own lives (self-directing). Research by Park (2005) has also indicated that associations between religion and adjustment are quite broad, vary across time and are mediated by meaning-making coping. The relationship between religion and wellbeing seems to be quite robust as religious involvement promotes healthy wellbeing and helps people cope with life stressors (Yendork, \& Somhlaba, 2017). These studies can be helpful in understanding the two-way relationship between religiosity and emotionavoidance coping on the one hand and religiosity and problem-focused coping on the other in our study. Lastly, our prediction on a positive correlation between religiosity and the ability to face challenges was confirmed.

\section{Limitations}

The results of this study represent the sample of international students who may not be representative of international students studying at Canadian universities for a number of reasons. Finding participants for this kind of research poses an immense challenge, especially when the institutions refuse 
to help in any way. Also, international students are very apprehensive when it comes to signing things like consent forms and taking surveys, so when one manages to locate international students, there is a good chance that they will not be interested in partaking in the research. Finally, any research on international students is at the mercy of the international student demographics population i.e., if the vast majority of international students are from a specific country (e.g., Indians at KPU and Chinese at Simon Fraser University, SFU), getting an even distribution of nationalities poses an even greater challenge. Moreover, international students make up a small portion of the total population of a university so the participants' pool is small by default.

Because some students report a better understanding of English than others, the comparison between nationalities might not be as accurate as, for example, Indian students may have had a stronger understanding of the questions than did the Chinese students. In addition, because of the language issues for some international students, the data on some social-psychological nature of questions might not be truly reflective of their actual feelings.

\section{Recommendations and implications}

We suggest that educational institutions may survey their international students on what services they need most. As international students pay a higher tuition fee compared to local students, more services should be offered to them.

In order to facilitate the adjustment of international students in Canada, educational institutions should make deals with community partners to provide reasonable assistance to international students such as sports tickets, discounts, and free invitations to social events.

The universities should make arrangements with the government agencies to facilitate visa services, work permits, family visits and provide legal services to help them. There is also a need for workshops to explain to the international students the health benefits and coverage available to them. Also, providing good counseling and psychological services may preempt psychological and emotional problems they might face during their studies. These services for international students may lessen their burden and unnecessary stress enabling them to focus on their studies.

To reduce the chances of their alienation, attention should also be paid to improve the social life of international students through creating opportunities for their participation in social and cultural activities on a regular basis. The institutions should have some programs to connect international students with the local students and the community. The community members may host international students on the eve of social and religious festivals to create a sense of inclusiveness in them.

As some international students faced stress to succeed, it is necessary for the university to promote communication between professors and 
international students. Regular meetings between international students and their professor may provide them the opportunity to share their problems with the faculty. This will also help the faculty to understand the issues faced by international students and timely help may be provided to them. Regular meetings between students and professors create learning from experience opportunity where students learn from their professors' experiences and get a better insight into the Canadian education system.

\section{Broader implications for higher education}

The fact that international students in our study were from the Asian countries implies that the outcome would be relevant to the educators and the students in these countries. A major outcome of our study is related to the benefit of the host country's language. Internationals, who had English language proficiency, had better adjustment and integration into the educational system as well as the social life in Canada. More generally, this suggests that international students should have some prior knowledge of the language of the country where they would like to pursue their studies. Besides its advantage in academia, it helps one to connect with the local people and become familiar with the culture of the host country. Knowledge of the language will enable internationals seeking part-time jobs to support their studies as many of them so desired.

The satisfaction of international students with an education in Canada may be relevant to the educators in the developing countries that follow traditional methods of instructions and learning that involve the one-sided passive transmission of information and rote memorization. The educators and the administrators in the developing countries may introduce some components of experiential learning used at Canadian universities on a trial basis to see their impact on the learning of the students. This may include actively involving the students in learning through group work, class activities and discussions, individual as well as group presentations, and community engagement through practicum and small research activities. The goal of these diverse learning approaches is enabling the students to relate and apply the learning materials to their everyday life experiences. Acquainting the students with diverse learning practices will not only benefit the students in their own countries but would also prepare them for future foreign studies. One of the issues which have generated some controversy among the faculty and the administration of Kwantlen Polytechnic University was the suspicion of plagiarism and cheating on the part of international students. Those who were familiar and/or were themselves part of the education system in the developing countries and came to Canada as immigrants knew the underlying reason for it. It was the habit and practice of rote memorization of the learning materials by some internationals which resulted in the literal reproduction of paragraphs after paragraphs from the books/online resources, which caused this controversy. This is an important issue which the students and educators 
from developing countries may attend to by practicing some of the aforementioned experiential approaches. Some educationists from the West have attempted to introduce diverse methods of teaching over rote memorization with considerable success (Richmond, 2007).

The findings of our study also suggest that communication with professors is instrumental in the success of students. Communication with the professors both in class and during their office hours can resolve educational and personal issues faced by the students. As internationals are a heterogeneous group belonging to different nationalities and cultures, communication helps professors as well to understand their specific issues leading to a direct and problem-focused solution.

That's being said, introducing diverse teaching-learning methods in the developing countries may not be a straightforward exercise as in Canada, where the faculty has the prerogative of academic freedom. The majority of the developing countries have a top-down process of governance and decision making. Except for minor sundry issues, any major change in the dissemination of instructions at the learning institutions might require political-administrative directives. In few known cases after introducing improvements in the educational system, these were rescinded because of a lack of resources, preparation and proper preparatory work. Nevertheless, with worldwide open communication, online courses and teaching, emerging new economies, and shrinking of the borders the gap between the developing and developed worlds may also shrink.

\section{References}

Alsahafi, N., \& Shin, S.-C. (2017). Factors Affecting the Academic and Cultural Adjustment of Saudi International Students in Australian Universities. Journal of International Students, 7(1), 53-72. https://doi.org/10.32674/jis.v7i1.245

Arthur, N., \& Flynn, S. (2011). Career development influences of international students who pursue permanent immigration to Canada. International Journal for Educational and Vocational Guidance, 11, 3, 221-237. DOI: https://doi.org/10.1007/s10775-011-9212-5

Ashdown, B.K., Homa, N., \& Brown, C.M (2014). Measuring Gender Identity and Religious Identity with Adapted Versions of the Multigroup Ethnic Identity Measure-Revised. Journal of Educational and Developmental Psychology; Vol. 4, No. 1; 2014 ISSN 1927-0526 E-ISSN 1927-0534

Baklashov, T.A., \& Kazakov, A.V. (2016). Challenges of International Students' Adjustment to a Higher Education Institution. International Journal of Environmental \& Science Education. 11, No. 8, 1821-1832 DOI: 10.12973/ijese.2016.557a

Bang, H. \& Montgomery, D. (2013). Understanding International Graduate Students Acculturation Using Q Methodology. Journal of College Student Development 54(4), 43-360. Johns Hopkins University Press. Retrieved February 8, 2018, from Project MUSE database. 
Benjamins, M. R., Ellison, C. G., \& Rogers, R. G. (2010). Religious involvement and mortality risk among pre-retirement aged U.S. adults. In C. E. Ellison \& R. A. Hummer (Eds.), Religion, families, and health: Population-based research in the United States. New Brunswick NJ: Rutgers University Press.

Brown, L., \& Jones, I. (2013). Encounters with racism and the international student experience. Studies in Higher Education, 38 (7), 1004-1019. doi:10.1080/03075079.2011.614940

Calder, M. J., Richter, S., Mao, Y., Burns, K. K., Mogale, R. S., \& Danko, M. (2016). International students attending Canadian universities: Their experiences with housing, finances, and other issues. The Canadian Journal of Higher Education, 46(2), 92-100.

Carver, C.S. (1997). You want to measure coping but your protocol's too long: Consider the Brief COPE. International Journal of Behavioral Medicine, 4, 92-100.

Deardorff, D.K. (2006). Identification and Assessment of Intercultural Competence as a Student Outcome of Internationalization. Journal of Studies in International Education, $\quad 10, \quad 241-266$. https://doi.org/10.1177/1028315306287002

Donelson, E. (1999). Psychology of religion and adolescents in the United States: Past to present. Journal of Adolescence, 22, 187-204.

Elturki, E., Liu, Y., Hjeltness, J., \& Hellmann, K. (2019). Needs, Expectations, and Experiences of International Students in Pathway Programs in the United States. Journal of International Students, 9(1), 192-210. https://doi.org/10.32674/jis.v9i1.274

Ge, L., Brown, D., \& Durst, D. (2019). Chinese international students' experiences in a Canadian university: Ethnographic inquiry with gender specification. Journal of International Students, 9 (2), 582-612. https://doi.org/10.32674/jis.v0i0.272

Gaudet, A. D., Ramer, L. M., Nakonechny, J., Cragg, J. J., \& Ramer, M. S. (2010). Small-group learning in an upper-level university biology class enhances academic performance and student attitudes toward group work. PloS One, 5(12), e15821. doi:10.1371/journal.pone.0015821

Gebhard. J.G. (2012). International students' adjustment problems and behaviors. Journal of International Students, 2, 184-193. ISSN: 2162-3104 Print/ ISSN: 2166-3750 Online

Hsieh, M. (2007). Challenges for international students in higher education: one student's narrated story of invisibility and struggle. College Student Journal, 41(2), 379-391.

Jenkins, J.R., \& Galloway, F. (2009). The adjustment problems faced by international and overseas Chinese students studying in Taiwan universities: A comparison of student and faculty/staff perceptions. Asia Pacific Education Review, 10, 159-168.

Khawaja, N. G., \& Stallman, H. M. (2011) Understanding the coping strategies of international students: A qualitative approach. Australian Journal of Guidance and Counselling, 21(2), 203-224.

Kingston, E, \& Forland, H (2007). Bridging the gap in expectations between International students and Academic staff. Journal of Studies in 
Koenig, H.G. (2009). Research on religion, spirituality, and mental health: A review. Canadian Journal of Psychiatry, 54(5), 283-91.

Koenig, H.G. (2012). Religion, Spirituality, and Health: The Research and Clinical Implications. International Scholarly Research Network. ISRN Psychiatry. Article ID 278730, 33 pages. doi:10.5402/2012/278730

Koenig, H. G., King, D. E., \& Carson, V. B. (2011). Handbook of religion and health. New York: Oxford University Press.

Krok, D. (2016). Sense of coherence mediates the relationship between the religious meaning system and coping styles in Polish older adults. Aging \& Mental Health, 20 (10), 1002-1009. doi:10.1080/13607863.2015.1056772

Lin, J., \& Qinghai, C. (1995). Academic pressure and impact on students' development in China. Mc Gill Journal of Education, 30, 149-168.

Mak, A.S., Bodycott, P., \& Ramburuth, P. (2015). Beyond Host Language Proficiency. Coping Resources Predicting International Students' Satisfaction. Journal of Studies in International Education, 19, 460-475. https://doi.org/10.1177/1028315315587109

Matsumoto, D. \& Juang, L. (2017). Culture and psychology: $6^{\text {th }}$ ed. Belmont, CA: Wadsworth.

MohdNajib, N.U, Yusof. N.A., \& Amin AkhavanTabassi, A.A. (2015). Living in Oncampus Student Housing: Students' Behavioural Intentions and Students' Personal Attainments. Procedia - Social and Behavioral Sciences, 170, 494503. https://doi.org/10.1016/j.sbspro.2015.01.052

Mooney, S.P., Sherman, M.F., \& Presto, C.L. (1991). Academic Locus of Control, Self-Esteem, and Perceived Distance from Home as Predictors of College Adjustment. Journal of Counselling \& Development, 69(5), 445-448. https://doi.org/10.1002/j.1556-6676.1991.tb01542.x

Nassar-McMillan, S.C., \& Hakim-Larson, J. (2011). Counseling considerations among Arab Americans. Journal of Counselling \& Development, 81, 150159. https://doi.org/10.1002/j.1556-6678.2003.tb00236.x

Neuby, B. L. (2012). Chinese Student Success in an Applied Academic Environment. Journal of Public Affairs Education, 18(4), 683-693.

Park, C. L. (2007). Religiousness/spirituality and health: A meaning systems perspective. Journal of Behavioral Medicine, 30, 319-328

Richardson, R. M., \& Smith, S. W. (2007). Professor-Student Power Distance Scale. Psychtests, doi: 10.1037/t63313-000

Richmond, J.E.D. (2007). Bringing critical thinking to the education of developing country professionals. International Education Journal, 8(1), 12924.http://iej.com.au

Rippentrop, E.A., Altmaier, E.M., Chen, J.J., Found, E.M., Keffala, V.J. (2005). The relationship between religion/spirituality and physical health, mental health, and pain in a chronic pain population. Pain, 116(3), 311-21. doi:10.1016/j.pain.2005.05.008

Robertson, M., Line, M., Jones, S., \& Thomas, S. (2010) International Students, Learning Environments and Perceptions: A case study using the Delphi technique, Higher $\quad$ Education $\quad$ Research \& Development, 19:1, 89102, doi: $10.1080 / 07294360050020499$ 
Russell, J., Rosenthal, D., \& Thomson, G. (2010). The international student experience: three styles of adaptation. Higher Education, 60(2), 235-249. doi:10.1007/s10734-009-9297-7

Sawir, E., Marginson, S., Deumert, A., Nyland, C., \& Ramia, G. (2008). Loneliness and international students: An Australian study. Journal of Studies in International Education, 12(2), 148-180. doi: 10.1177/102831530729969.

Scott, C., Safdar, S., Desai Trilokekar, R., \& El Masri, A. (2015). International Students as 'Ideal Immigrants' in Canada: A disconnect between policy makers' assumptions and the lived experiences of international students. Comparative and International Education / Éducation Comparée et Internationale, 43, 3, Article 5. Available at:

http://ir.lib.uwo.ca/cie-eci/vol43/iss3/5

Shah, A.A. (2017). Physical, mental and spiritual health: Triad of happiness and tranquility. Physical, mental and spiritual health: Triad of happiness and tranquility. In S. Batool (Ed.), Proceedings of International Conference of "Health psychology: Issues and Challenges" (pp. 5-32). Lahore: Pakistan. Department of Psychology, GC University.

Sherry, M., Thomas, P., \& Chui, W. H. (2010). International students: A vulnerable student population. Higher Education, 60 (1), 33-46. doi: 10.1007/s10734009-9284-Z

Siddiqui, S., \& Shah, A.A. (1997). Siddiqui-Shah depression scale (SSDS): Development and validation. Psychology and Developing Societies: A Journal, 9, 245-262.

Tatar, S. (2005). Classroom participation by international students: The case of Turkish graduate students. Journal of Studies in International Education, 9(4), 337-355. doi:10.1177/1028315305280967

Triandis, H. C., Leung, K., Villareal, M., \& Clack, F. L. (1985). Allocentric vs. idiocentric tendencies: Convergent and discriminant validation. Journal of Research in Personality, 19, 395-415. doi:10.1016/0092-6566(85)90008-X

Universities Canada (2017). https://www.univcan.ca/media-room/mediareleases/canadas-global-moment-students-around-world-choose-canada/)

Veraevel, L.N. (2014). Canadian post-secondary students, stress and academic performance-A socio-ecological approach. Electronic thesis and dissertation repository. 2657. https://ir.lib.uwo.ca/etd/2657

Wang, J. (2009). A study of resiliency characteristics in the adjustment of international graduate students at American universities. Journal of Studies in International Education, 13(1), 22- 45.

Werner, E., \& Smith, R. (1989). Vulnerable but invincible: A longitudinal study of resilient children and youth. New York: Adams, Bannister, and Cox.

Yendork, S., J., \& Somhlaba, N. Z. (2017). 'I am happy because of God': Religion and spirituality for well-being in Ghanaian orphanage-placed children. Psychology of Religion and Spirituality, 9, 32-39. doi:10.1037/rel0000094

Zullig, K.J., Ward, R.M. \& Horn, T. (2006). The association between perceived spirituality, religiosity, and life satisfaction: The mediating role of self-rated health. Social Indicator Research, 79: 255. doi:10.1007/s11205-005-41275. 


\section{Author bios}

Syed Ashiq Ali Shah, Dr Phil, is a professor in the department of psychology, Kwantlen Polytechnic University, BC, Canada. He has also worked at the universities in Germany, Pakistan and Malaysia. His research interests include social-psychological issues, cross-cultural differences in human behaviour, development of indigenous scales and the role of religion and spirituality in human behaviour. He has published in the areas of prejudice and stereotypes, social attitudes, depression, child abuse, drug abuse, culture's impact on human behaviour, spirituality and religiosity in psychotherapy. He is the consulting and associate editor of a number of international Journals.

Alexander Lopes, BA, is a graduate in psychology from Kwantlen Polytechnic University. He has worked as a research assistant in different research projects including challenges faced by international students at KPU. $\mathrm{He}$ is currently pursuing a degree in specialized nursing. $\mathrm{He}$ has multidisciplinary interests with regards to research.

Linah Kareem, BA, is a graduate in psychology from Kwantlen Polytechnic University. She has worked as a research assistant in research project on "challenges faced by international students at KPU." She is working as a student advisor at Kwantlen Polytechnic University. 